\title{
Evaluasi Kinerja Metode PCA/LPP Pada Sistem Pengenalan Citra Wajah Manusia
}

\author{
Oleh \\ Ni Wayan Marti \\ Jurusan Manajemen Informatika, FTK - Undiksha
}

\begin{abstract}
Abstrak
Sistem identifikasi personal yang berbasis pengenalan wajah dengan tingkat akurasi yang optimal sangat diperlukan untuk mengidentifikasi seseorang secara tepat yang dapat dimanfaatkan dalam suatu sistem pengamanan elektronik. Pada penelitian ini telah dibangun suatu sistem pengenalan citra wajah manusia dengan menerapkan dua metode pada tahap ekstraksi ciri wajah, yaitu metode Principal Component Analysis (PCA) digabung dengan metode Locality Preserving Projection (LPP) atau yang akan disebut dengan metode PCA/LPP. Sedangkan pada tahap pengklasifikasian digunakan metode linier yaitu jarak euclidean dari ketetanggaan terdekat. PCA digunakan untuk mereduksi dimensi citra wajah yang besar dengan vektor basis yang disebut Eigenfaces. Sedangkan metode Locality Preserving Projection merupakan metode linier yang dapat menemukan manifold nonlinier data pada dimensi rendah. Vektor-vektor basis yang dihasilkan LPP disebut Laplacianfaces. Untuk tahap uji coba sistem, digunakan basis data wajah Yale yang telah dinormalisasi. Tingkat pengenalan optimal yang diperoleh dengan menggunakan metode PCA adalah $82.67 \%$, sedangkan dengan metode PCA/LPP adalah $86.67 \%$.
\end{abstract}

Kata-kata kunci : PCA, LPP, Eigenfaces, Laplacianfaces

\begin{abstract}
Personal identification system based on face recognition which has a good rate recognition can be used in electronical security system. In this research has been developed a human face recognition that use two methods on feature extraction stage, that are Principal Component Analysis (PCA) and Locality Preserving Projection (LPP). And using a nearest neighbor classifier in last stage. PCA is used to reduce dimension to obtain the orthonormal basis vectors which is called Eigenfaces. LPP is a linear method which is able to find nonlinear manifold of data at low dimension. Basis vectors which are yielded is called Laplacianfaces. The experiment in this research confronted using normalized face databases, i.e. Yale databases. The optimal recognition accuracy of this sytem using
\end{abstract}


Yale database with PCA methode is $82.67 \%$, and with PCA/LPP methode is $86.67 \%$.

Keywords : PCA, LPP, Eigenfaces, Laplacianfaces,

\section{PENDAHULUAN}

Pengenalan wajah otomatis merupakan area penelitian yang sangat pesat berkembang beberapa tahun terakhir. Berbagai aplikasi yang menggunakan citra wajah sebagai sumber informasi telah banyak dihasilkan. Hal ini dikarenakan secara umum citra wajah dapat memberikan informasi khusus yang berkaitan dengan identifikasi personal berbasis pengenalan wajah yang dapat dimanfaatkan dalam suatu sistem pengamanan elektronik.

Secara garis besar metode yang digunakan dalam proses pengenalan wajah ada tiga macam yaitu metode holistik, metode berdasarkan ciri, dan metode hybrid. Diantara metode holistik, metode berdasarkan penampakan (appearance based-methode) adalah teknik yang sangat sukses untuk pengenalan wajah pada beberapa tahun terakhir ini (Cai et al, 2005, He et al, 2005)

Ketika menggunakan metode berdasarkan kenampakan, citra berukuran nxm piksel digambarkan sebagai sebuah vektor dalam ruang yang berdimensi $n x m\left(R^{n x m}\right)$. Dalam prakteknya, ruang yang berdimensi nxm ini terlalu besar untuk melakukan pengenalan wajah yang cepat. Untuk memecahkan permasalahan ini biasanya dilakukan dengan menggunakan teknik pereduksian.

Metode PCA hanya bertujuan untuk menyajikan struktur global dari ruang citra asal. Pada banyak aplikasi dunia nyata, struktur lokal lebih penting. Locality Preserving Projection (LPP) merupakan teknik linier yang dapat menyajikan struktur lokal manifold yang dimodelkan dengan adjacency graph dari titik-titik data pelatihan. LPP merupakan metode linier, akan tetapi dapat menemukan manifold nonlinier data pada dimensi rendah (Marti, 2006). 
Pada penelitian ini telah dibangun sistem pengenalan citra wajah manusia dengan menggunakan pendekatan baru untuk analisis wajah (representasi dan pengenalan), yaitu menggunakan perpaduan antara metode PCA dengan LPP (PCA/LPP). Pada sistem ini setiap citra wajah dipetakan ke dalam subruang yang dbentuk LPP yang berdimensi lebih rendah, yang dikarakteristikkan oleh sekumpulan citra ciri (feature image) yang disebut Laplacianfaces. Selanjutnya pada subruang wajah yang dibentuk oleh Laplacianfaces ini akan dilakukan pengklasifikasian dengan menggunakan jarak eucledian dari ketetanggaan terdekat.

\section{Principle Component Analysis (PCA)}

PCA merupakan sebuah tehnik linier yang digunakan untuk memproyeksikan data yang berdimensi tinggi ke dalam subruang yang berdimensi lebih rendah. Teknik PCA dikenal sebagai metode Kurhunen-Loeve, yang memilih sebuah proyeksi linier untuk mereduksi dimensi ruang citra yang memaksimalkan penyebaran (scatter) dari seluruh data pelatihan yang diproyeksikan.

Turk and Pentland (1991) mengatakan bahwa jika ada $M$ buah citra wajah yaitu $\Gamma_{1}, \Gamma_{2}, \ldots, \Gamma_{M}$ yang digunakan dalam pelatihan dan masingmasing citra wajah dipandang sebagai sebuah vektor wajah yang panjangnya $\mathrm{N}$ (baris x kolom). Rata-rata wajah dari kumpulan data yang dilatih ini dapat diperoleh dari $\Psi=\sum_{i=1}^{M} \Gamma_{i}$ (2.1). Kemudian, setiap vektor wajah dikurangkan dengan rata-rata wajah, dengan rumus $\Phi_{i}=\Gamma_{i}-\Psi(2.2)$.

Kumpulan dari vektor-vektor yang sangat besar ini merupakan syarat untuk analisis komponen utama (principal component), yang mana mencari sekumpulan $\mathrm{m}(\mathrm{m} \ll \mathrm{N})$ buah vektor orthonormal $\mu_{k}$ yang bersesuaian dengan nilai eigen $\lambda_{k}$ terbaik yang menggambarkan pendistribuasian data. Vektor $\mu_{k}$ dan scalar $\lambda_{k}$ masing-masing merupakan vektor eigen dan nilai eigen dari matriks kovarian : 


$$
\begin{aligned}
C & =\frac{1}{M} \sum_{i=1}^{M} \Phi_{i} \Phi_{i}^{T} \\
& =A A^{T}
\end{aligned}
$$

dimana matriks $A=\Phi_{1}, \Phi_{2}, \ldots, \Phi_{N_{-}}{ }^{-}$. Matriks kovarian $C$ akan berukuran $N x N$, dan digunakan untuk mencari $N$ buah vektor eigen dan nilai eigen. Nilai ini memiliki dimensi yang sangat besar untuk proses citra. Untuk itu secara komputasi, diperlukan metode yang lebih sederhana untuk mendapatkan vektor eigen-vektor eigen ini. Untuk mengatasi hal ini, dapat digunakan dimensi matriks yang lebih kecil yaitu $M x M$ untuk proses PCA, dimana $M$ merupakan jumlah citra yang digunakan dalam pelatihan (Turk and Pentlant, 1991). Oleh Yambor (2000), cara tersebut di atas dikenal dengan metode Snapshot Eigenfaces. Dengan analisa ini, perhitungan menjadi berkurang secara dramatis, dari ukuran jumlah piksel $N$ menjadi $M(M<<N)$. Pemecahan metode ini digunakan jika jumlah data pelatihan jauh lebih kecil dari dimensi vektor wajah.

Menurut teorema aljabar linier, bahwa nilai eigen dari $A A^{T}$ dan $A^{T} A$ adalah sama. Selanjutnya, vektor eigen dari $A A^{T}$ adalah sama seperti vektor eigen dari $A^{T} A$ yang dikalikan dengan matriks $\mathrm{A}$ dan dinormalisasi.

\section{Locality Preserving Projection (LPP)}

LPP merupakan algoritma baru untuk pembelajaran subruang penyajian secara lokal. LPP mencari arah untuk menyajikan geometri instrinsik dari data pelatihan dan struktur lokal (He, et al, 2005). Fungsi obyektif dari LPP, adalah sebagai berikut :

$$
\min \sum_{i j}\left(f_{i}-f_{j}\right)^{2} W_{i j}
$$

dimana $f_{i}$ merupakan penggambaran satu dimensi dari $\mathrm{x}_{\mathrm{i}}$ (data asal/pelatihan) dan matriks $W$ merupakan matriks similarity. $W$ dapat didefinisikan sebagai berikut Error! Reference source not found.:

$$
W_{i j}= \begin{cases}e^{-\frac{\mid x_{i}-x_{j} \|^{2}}{t}}, & \text { jika } \mathrm{x}_{\mathrm{i}} \text { dan } \mathrm{x}_{\mathrm{j}} \text { berada pada kelas yang sama } \\ 0 \quad, \text { jika } \mathrm{x}_{\mathrm{i}} \text { dan } \mathrm{x}_{\mathrm{j}} \text { berada pada kelas yang berbeda }\end{cases}
$$


Peminimalan fungsi obyektif, mencoba untuk memastikan bahwa antara titik $x_{i}$ dan $x_{j}$ adalah benar-benar dekat yaitu berada dalam kelas yang sama.

Misal diketahui $\boldsymbol{a}$ merupakan sebuah vektor transformasi, dimana $f^{T}=a^{T} X$, dimana vektor kolom ke- $i$ dari $X$ adalah $x_{i}$. Fungsi obyektif di atas dapat direduksi ke dalam bentuk $a^{T} X L X^{T} a \quad$ (2-6) dimana $X=\mathbf{L}_{1}, x_{2}, \ldots, x_{M}{ }_{-}^{-}$, dan $D$ adalah matriks diagonal yang yang isinya adalah jumlah kolom (atau baris karena $W$ simetris) dari $W, D_{i i}=\Sigma_{j} W_{i j}$. $L=D-W$ adalah matriks Laplacian. Matriks $D$ memberikan pengukuran yang natural pada titik-titik data.

Selanjutnya vektor basis dari LPP akan diperoleh dengan cara memecahkan permasalahan minimalisasi untuk menemukan :

$$
a_{\text {opt }}=\arg \min a^{T} X L X^{T} a
$$

dengan batasan :

$$
a^{T} X D X^{T} a=1
$$

Vektor transformasi a yang meminimalkan fungsi objektif diberikan dengan solusi nilai eigen minimum untuk permasalahan umum vektor eigen, berikut ini :

$$
X L X^{T} a=\lambda X D X^{T} a
$$

Matriks $X L X^{T}$ dan $X D X^{T}$ adalah simetris dan positive semi definite karena matriks Laplacian $L$ dan matriks diagonal $D$ keduanya simetris dan positive semi definite. Vektor transformasi $a_{o p t}$ yang disebut sebagai Laplacianfaces adalah tidak orthonormal.

\section{METODOLOGI PENELITIAN}

Secara umum, desain sistem pengenalan citra wajah manusia yang menerapkan Metode Locality Preserving Projection (LPP) adalah sebagai berikut : 


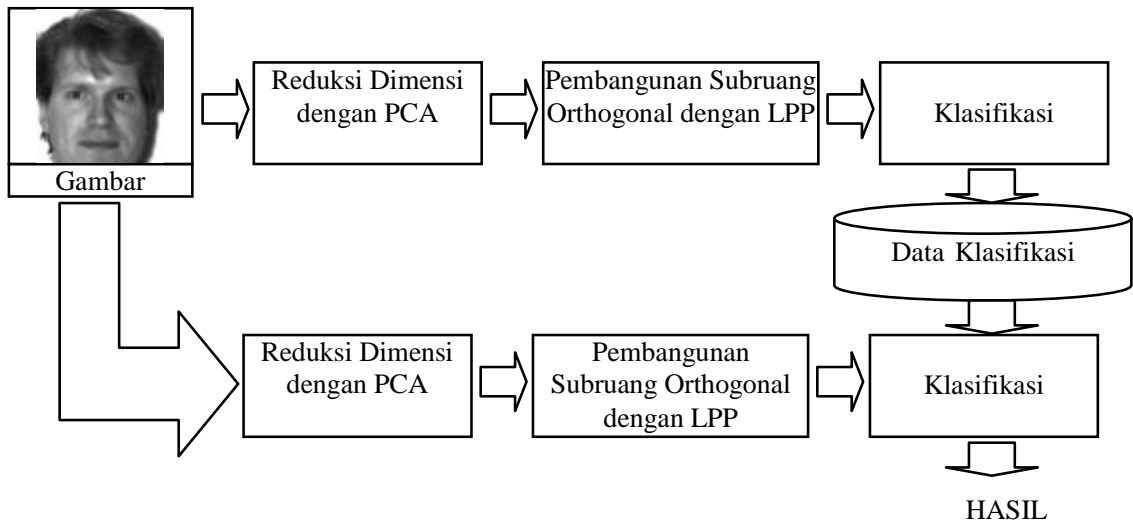

Gambar 1 Desain sistem pengenalan citra wajah manusia menggunakan Metode Locality Preserving Projection (LPP)

\section{Algoritma dari desain sistem di atas adalah sebagai berikut :}

\section{Vektor dan Ruang Wajah}

Sebuah citra wajah dapat dipandang sebagai sebuah vektor yang terletak dalam sebuah ruang yang disebut ruang citra (image space). Sebuah citra tersusun atas piksel-piksel yang masing-masing piksel memiliki nilai. Apabila lebar dan tinggi sebuah citra adalah $\mathrm{w}$ dan $\mathrm{h}$, maka banyaknya komponen dari vektor ini adalah wxh piksel, seperti yang terlihat pada Gambar 2 di bawah ini

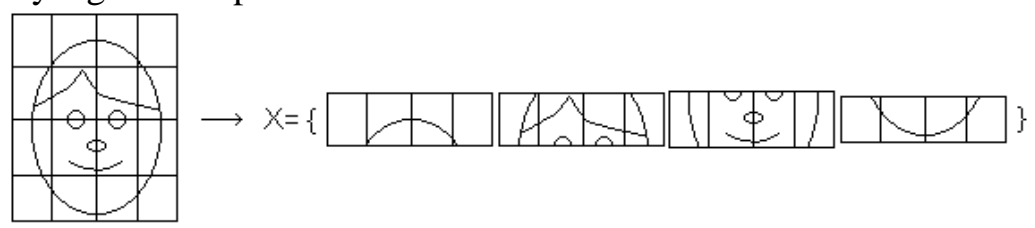

Gambar 2 Formasi Vektor dari sebuah citra wajah

\section{Reduksi Dimensi}

Teknik yang digunakan untuk mereduksi dimensi citra yang tinggi menjadi subruang citra yang lebih rendah adalah teknik PCA. PCA akan membangkitkan suatu himpunan basis orthonormal yang disebut komponen utama yang memaksimalkan sebaran dari seluruh data pelatihan $\left\{\mathrm{x}_{\mathrm{i}}\right\}$ yang diproyeksikan.

Terdapat $X=\mathbf{Y}_{1}, X_{2}, \ldots, X_{M_{-}}{ }_{-}^{-}$yang merupakan himpunan data pelatihan dari citra wajah asal berdimensi $N$ dengan rata-rata wajah 
nol. Selanjutnya vektor eigen dan nilai eigen akan dihitung menggunakan metode Snapshot Eigenfaces untuk tujuan menghemat biaya komputasi, yaitu sebagai berikut :

$$
\begin{aligned}
& \left(X^{T} X\right) \Psi=\Psi \Lambda \\
& P=X \Psi
\end{aligned}
$$

Dengan $\Lambda=\operatorname{diag}\left\{\lambda_{1}, \lambda_{2}, \ldots, \lambda_{M}\right\}$ dan $P=\boldsymbol{\Phi}_{1}, \Phi_{2}, \ldots, \Phi_{M}{ }_{-}^{-}$Jika diasumsikan bahwa nilai eigen telah terurut secara decreasing order, $\lambda_{1} \geq \lambda_{2} \geq \cdots \geq \lambda_{M}$, maka $m$ vektor eigen terbesar pertama digunakan untuk mendefinisikan matrix $A$

$$
A=\boldsymbol{\Gamma}_{1}, \Phi_{2}, \ldots, \Phi_{m_{-}}^{-}
$$

Himpunan ciri baru $Z$ dengan dimensi $m(m \perp N)$ dapat dihitung dengan rumusan

$$
Z=A^{T} X
$$

Untuk alasan kesederhanaan, untuk pada tahap selanjutnya masih akan menggunakan $x$ untuk menotasikan citra pada subruang PCA. Selanjutnya matriks transformasi PCA (A) dinotasikan dengan $A_{P C A}$.

\section{Membangun graph ketetanggaan terdekat}

Dibangun graph $\mathrm{G}$ menotasikan sebuah graph dengan $n$ node. Node ke- $i$ menggambarkan citra wajah $x_{i}$. Karena penelitian dilakukan pada lingkup terawasi, maka edge akan ditempatkan diantara node $i$ dan $j$ jika $x_{i}$ dan $x_{j}$ terletak pada kelas yang sama. Graph ketetanggaan terdekat yang bangun merupakan perkiraan dari struktur manifold lokal.

\section{Pembobotan dengan Heatkernel}

Jika node $i$ dan $j$ terhubung maka diberi nilai $W_{i j}=e^{-\frac{\mid x_{i}-x_{j} \|^{2}}{t}}$, dan Jika node $i$ dan $j$ tidak terhubung maka diberi nilai nol. 


\section{Pemetaan Eigen}

Penghitungan vektor eigen dan nilai eigen untukpermasalahan vektor eigen yang umum :

$$
X L X^{T} \mathbf{w}=\lambda X D X^{T} \mathbf{w},
$$

dimana $D$ adalah matriks diagonal yang isinya adalah jumlah kolom (atau baris karena $S$ adalah simetris) dari matriks $S, D_{i i}=\Sigma_{j} S_{i j} . L=$ $D-S$ adalah matriks Laplacian.

Misalkan, $\left\{w_{1}, w_{2}, \ldots, w_{k-1}\right\}$ menjadi pemecahan dari persamaan 3.5 yang terurut berdasarkan nilai eigen terkecil, $0 \leq \lambda_{0} \leq \lambda_{1} \leq \cdots \leq \lambda_{k-1}$. Nilai eigen - nilai eigen ini sama atau lebih besar dari pada 0 (nol) karena matriks $X L X^{T}$ dan $X D X^{T}$ keduanya adalah simetris, dimana akan disimpan dengan cara sebagai berikut:

$$
\begin{aligned}
& x \rightarrow y=W^{T} x, \\
& W=W_{P C A} W_{L P P,} \\
& W_{L P P}=\left[w_{1}, w_{2}, \ldots, w_{k-1}\right]
\end{aligned}
$$

dimana $y$ adalah vektor berdimensi k. $W$ adalah matriks transformasi. $A_{L P P}$ merupakan vektor basis yang disebut Laplacianfaces

\section{Klasifikasi}

Metode pengklasifikasian yang digunakan adalah jarak euclidean dari ketetanggaan terdekat. Jarak euclidean antara dua buah titik pada sub ruang yang berdimensi lebih rendah dapat dihitung dengan cara sebagai berikut :

$$
\begin{aligned}
\operatorname{dist}\left(y_{i}, y_{j}\right) & =\left\|y_{i}-y_{j}\right\| \\
& =\left\|A^{T} x_{i}-A^{T} x_{j}\right\| \\
& =\left\|A^{T}\left(x_{i}-x_{j}\right)\right\| \\
& =\sqrt{\left(x_{i}-x_{j}\right)^{T} A A^{T}\left(x_{i}-x_{j}\right)}
\end{aligned}
$$




\section{PEMBAHASAN}

Uji coba terhadap sistem pengenalan citra wajah manusia yang dikembangkan pada penelitian ini dilakukan pada sebuah basis data wajah baku yaitu Yale. Sebagai pemrosesan awal, seluruh citra akan dinormalisasi dan mata diluruskan pada posisi yang sama. Seluruh Basis Data Yale memuat 15 orang dengan masing-masing memiliki 11 citra. Subyek bervariasi terhadap jenis kelamin, ekspresi wajah (normal, senang, sedih, mengantuk, terkejut, dan berkedip), kondisi pencahayaan (arah kiri, tengah dan kanan) dan asesoris wajah (misalnya pemakaian kacamata). Citra hasil normalisasi yang digunakan berukuran 104x136 piksel dari citra asal yang berukuran 320x243 piksel.

Pengujian pada sistem pengenalan wajah yang dikembangkan pada penelitian ini dilakukan dengan memisahkan data citra wajah menjadi dua himpunana yang saling pisah (disjoint) yaitu himpunan citra pelatihan dan citra pengujian. Perhitungan persentase dari keberhasilan pengenalan wajah dilakukan pada himpunan citra pengujian.

Proses pembelajaran pada basis data wajah Yale dilakukan pada tiga variasi pengujian, yaitu:

- Uji Yale 5, pada uji ini diambil lima buah pose dari tiap subyek sebagai anggota himpunan data pelatihan dan enam pose lainnya dimasukkan pada data pengujian.

- Uji Yale 6, pada uji ini diambil enam buah pose dari tiap subyek sebagai anggota himpunan data pelatihan dan lima pose lainnya dimasukkan pada data pengujian.

- Uji Yale 7, pada uji ini diambil tujuh buah pose dari tiap subyek sebagai anggota himpunan data pelatihan dan empat pose lainnya dimasukkan pada data pengujian.

Pengujian dilakukan pada metode PCA dan metode PCA/LPP. Berikut ini adalah tabel dari tingkat pengenalan pada tiga variasi pengujian pada basis data wajah Yale, adalah sebagai berikut : 
Tabel 1 Hasil pengujian sistem

\begin{tabular}{|c|c|c|c|}
\hline \multirow{2}{*}{ Metode } & $\begin{array}{c}\text { Variasi } \\
\text { Pengujian }\end{array}$ & $\begin{array}{c}\text { Presentase } \\
\text { Pengenalan }\end{array}$ & Dimensi \\
\hline \multirow{3}{*}{ PCA/LPP } & Yale 5 & $84.44 \%$ & 30 \\
\cline { 2 - 4 } & Yale 6 & $86.67 \%$ & 24 \\
\cline { 2 - 4 } & Yale 7 & $88.33 \%$ & 13 \\
\hline \multirow{3}{*}{ PCA } & Yale 5 & $81.11 \%$ & 43 \\
\cline { 2 - 4 } & Yale 6 & $82.67 \%$ & 15 \\
\cline { 2 - 4 } & Yale 7 & $80.00 \%$ & 40 \\
\hline
\end{tabular}

Dari hasil pengujian di atas, terlihat bahwa kinerja dari metode $P C A, P C A / L P P$ yang digunakan sangat bervariasi dengan jumlah dimensi. Ini diakibatkan karena adanya faktor pembobotan pada Metode PCA/LPP pada tahap penerapan LPP-nya. Hasil pengujian menunjukkan bahwa hasil terbaik diperoleh dengan menggunakan PCA/LPP yaitu penggabungan antara metode PCA dengan metode LPP. Tidak ada perbaikan yang signifikan jika dimensi yang digunakan lebih dari pada dimensi optimal di atas, seperti yang terlihat pada Gambar 3 di bawah ini

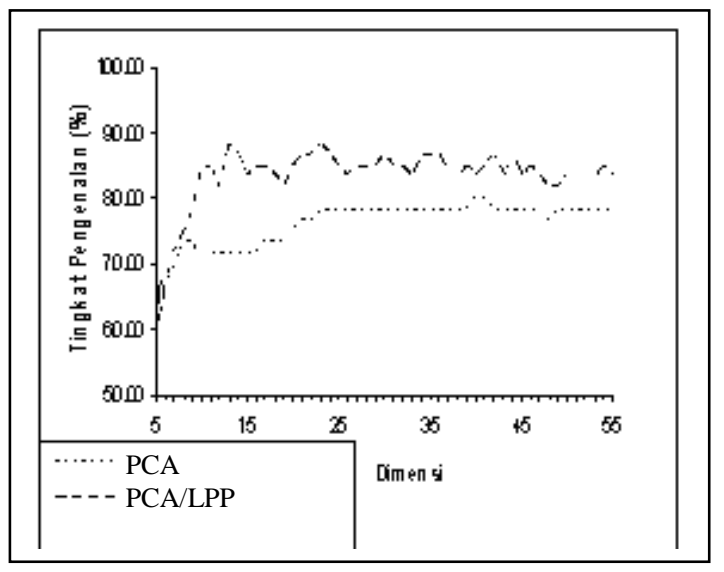

Gambar 3 Grafik Tingkat pengenalan sistem terhadap besarnya dimensi

Dari hasil pengujian yang diperoleh menggunakan Metode PCA, pada uji Yale 7 terlihat bahwa tingkat pengenalan yang diperoleh menurun, ini diakibatkan karena adanya faktor pencahayaan pada citra Basis Data Yale. 


\section{PENUTUP}

Berdasarkan uji coba dan analisis hasil pengujian terhadap Sistem Pengenalan Citra Wajah Menggunakan Metode PCA/LPP dapat disimpulkan sebagai berikut :

- Sistem pengenalan wajah yang dikembangkan mampu melakukan pengenalan yang optimal pada subruang wajah dengan mempertimbangkan dua aspek yang saling berpengaruh yaitu, aspek reduksi terhadap jumlah data yang digunakan pada klasifikasi serta peningkatan kemampuan pendiskriminasiannya.

- Untuk uji coba perangkat lunak, digunakan basis data wajah baku yaitu The Yale Face Database (Yale)

- Tingkat pengenalan optimal yang diperoleh dengan menggunakan metode PCA adalah $82.67 \%$, dan dengan metode gabungan yaitu PCA/LPP adalah $88,33 \%$.

- Metode $P C A / L P P$ lebih diskriminan dibandingkan dengan metode $P C A$ untuk tujuan pengklasifikasian

\section{DAFTAR PUSTAKA}

Cai, D., He, X., and Han, J. (2005) Using Graph Model for Face Analysis, University of Illinois at Urbana-Champaign and University if Chicago.

He, X., Yan, S., Hu, Y., Niyogi, P., and Zhang, H. J. (2005) Face Recognition Using Laplacianfaces, IEEE transactios on Pattern analysis and machine intelligence, 27, 328-340.

Marti, Ni Wayan, (2006), Pengenalan Wajah pada Subruang Menggunakan Orthogonal Laplacianfaces, Prosiding Seminar Nasional Pascasarjana VI 2006 ITS, vol. 2.

Marti, Ni Wayan, (2007), Penerapan Teknik Eigenfaces Pada Sistem Pengenalan Wajah, Jurnal Pendidikan Teknologi dan Kejuruan, 4(1), $15-23$ 
Soelaiman, R., (2006), Sistem Pengenalan Wajah dengan Penerapan Algoritma Genetika pada Optimasi Basis Eigenface dan Proyeksi Fisherface, Tesis Master, Universitas Indonesia

Turk, M and Pentlant, A. (1991) Face Recognition Using Eigenfaces, Proc. IEEE Conf. of Computer Vision and Pattern Recognition, 13, 586-591.

Yambor, W.S. (2000) Analysis of PCA-Based and Fisher DiscriminantBased Image Recognition Algorithms, Tesis of Master, Colorado State University. 